Mackenzie, E., McMaugh, A., \& Van Bergen, P. (2020). Digital support seeking in adolescent girls: A qualitative study of affordances and limitations. Cyberpsychology: Journal of Psychosocial Research on Cyberspace, 14(3),

Article 5. https://doi.org/10.5817/CP2020-3-5

\title{
Digital Support Seeking in Adolescent Girls: A Qualitative Study of Affordances and Limitations
}

\author{
Erin Mackenzie ${ }^{1}$, Anne McMaugh², \& Penny Van Bergen² \\ ${ }^{1}$ Centre for Educational Research, Western Sydney University, Australia \\ ${ }^{2}$ Department of Educational Studies, Macquarie University, Australia
}

\begin{abstract}
While digital communication is almost universal amongst adolescents, we do not yet know why adolescent girls seek support electronically or how they perceive this support. The prevalence of adolescent girls' informal digital support seeking was determined by a self-report questionnaire with 186 early and middle adolescent girls ( $M_{\text {age }}=$ 13.64 years), drawn from four socioeconomically advantaged schools in Australia. Digital support seeking from friends was extremely common, with $73.66 \%$ seeking emotional support and $85.48 \%$ seeking academic support. Next, to determine perceptions of digital support seeking, we conducted in-depth semi-structured interviews with a representative subsample of 31 girls ( $M_{\text {age }}=13.95$ years). Interview data was analysed using inductive thematic analysis. Themes of friendship and emotional self-regulation emerged as perceived benefits. Girls perceived digital support to be poorer in quality than face-to-face support, and were particularly concerned about limitations to privacy and the disclosure of confidential information. Several maladaptive behaviours such as using digital support seeking to conceal or avoid emotion were identified. There was variation in the attitudes of the sample, and four groups of girls with distinct attitudes towards digital emotional support seeking were identified. Implications for supporting adolescents to effectively seek support electronically and face-to-face are discussed.
\end{abstract}

Keywords: Digital support seeking; adolescent girls; support seeking; coping; friendship; trust; emotion regulation

\section{Introduction}

Seeking support is an important way of coping when a stressful experience outweighs an individual's ability to cope alone (Skinner \& Zimmer-Gembeck, 2016). While some adolescents access help from formal sources of support such as mental health professionals and teachers, they are more likely to seek informal support from friends and parents (Camara et al., 2017; Wilson et al., 2005). This support can include emotional support, information and resources, and a sense of connection or relatedness with others (Skinner et al., 2003; ZimmerGembeck \& Skinner, 2008). Digital communication devices provide individuals with an alternative mode through which to seek and receive social support (Tanis, 2007). There is a considerable body of research focusing on adolescents' use of formal support in digital contexts (see Clarke, Kuosmanen, \& Barry, 2015; Kauer et al., 2014; Rice et al., 2014 for reviews). Similarly, there is increasing evidence of the use of digital communication devices in the provision and seeking of support in health-related contexts (e.g. Love et al., 2012; Schwieger et al., 2016). More recently, research attention has focussed on informal digital support seeking as a way of coping with everyday stress (Duvenage et al., 2020; Frison \& Eggermont, 2015; Vermeulen et al., 2018a). This shift reflects adolescents' almost ubiquitous use of digital devices to interact with friends and others (Anderson \& Jiang, 2018a), and the critical role of friends as informal support providers in adolescence (Zimmer-Gembeck \& Skinner, 2011). 
Informal support seeking is defined as the act of obtaining assistance to cope with stressors from informal sources, such as parents, friends, or peers (Heerde \& Hemphill, 2018). Although adolescents continue to report that friends and parents are their first sources of support when faced with a problem (Spears et al., 2015), they also turn to digital sources of support (Bonetti et al., 2010; Rickwood et al., 2015). While a range of terms, including online support (Tanis, 2007) and computer-mediated support (Rains \& Wright, 2016), are used in the literature, in this paper we use digital support seeking to refer to the use of digital media devices to seek informal support through social networking sites (SNSs), instant messaging (IMing), text messaging, and email.

In this paper, we investigate early and middle adolescent girls' informal support seeking in digital media contexts. We focused on adolescent girls because robust evidence from the coping literature suggests that girls are more likely to seek support than boys (e.g. Eschenbeck et al., 2007; Fallon \& Bowles, 1999). Girls are also more likely to experience internalising disorders than boys, including depression (Colarossi \& Eccles, 2003; Hankin et al., 2007; Zahn-Waxler et al., 2008) and anxiety (Roza et al., 2003), which may indicate a greater need for support. Recent research also suggests that girls are more likely to seek support using the internet (Bullot et al., 2017; Glüer \& Lohaus, 2016) and report receiving support from online sources (Anderson \& Jiang, 2018a). Finally, we specifically focused on seeking support from friends, because adolescents are most likely to interact with their friends online (Reich et al., 2012). Thus, adolescent girls appear to be a particularly important population in which to examine affordances and limitations of digital support seeking.

\section{Coping, Support Seeking, and Digital Media}

Coping is a regulatory process that is enacted in response to stress (Compas, 2009). The ways in which adolescents respond to stress can have significant short- and long-term implications for their psychosocial functioning (Compas et al., 2001; Skinner et al., 2003). While there are many theoretical models of coping, developmental perspectives highlight both individual differences and the development of coping across childhood, adolescence, and early adulthood (Zimmer-Gembeck \& Skinner, 2016). Although developmental definitions of coping vary, they converge on one central tenet of coping defined as "regulation under stress" (Compas et al., 2001; Eisenberg et al., 1997; Skinner \& Zimmer-Gembeck, 2016). Developmental coping perspectives also recognise that coping is constrained by the emotional, social, and cognitive development of the child or adolescent (Compas et al., 2001), and focus on how changes in coping are related to developmental processes (Compas, 1998).

One key objective of the developmental study of coping is to identify typical patterns of changes in coping. In early adolescence, for example, improvements in metacognition should lead to an increased ability to match coping strategies with the type of stressor, and allow adolescents to reflect on their own coping (Compas et al., 2001; Zimmer-Gembeck \& Skinner, 2016). During middle adolescence, the increased salience of identity and autonomy is expected to drive increases in self-reliance in managing stressors (Crystal et al., 2008; Skinner \& ZimmerGembeck, 2016). Further, a greater range of coping strategies should be available to adolescents (Compas et al., 2001; Donaldson et al., 2000). While these changes indicate that adolescents should have increased capacity to cope with stress, emotion regulation and response inhibition are not yet fully developed in adolescence (Rahdar \& Galván, 2014; Steinberg, 2005), which may lead to adolescents employing less adaptive coping strategies under high stress situations (Zimmer-Gembeck \& Skinner, 2016).

While there are many different coping strategies, support seeking represents a frequently used way of coping with stress for adolescents (Skinner et al., 2003). Support seeking is also varied, with different sources of support (e.g. parents, friends, peers) each able to offer different kinds of support (e.g. emotional, informational, instrumental) (Malecki \& Demary, 2002). Peer relationships are enormously important in adolescence, more so than any other stage of life (Albert et al., 2013). Being accepted by peers activates reward pathways in the adolescent brain (Crone \& Konijn, 2018), meaning that peers are highly influential in decision-making (Chein et al., 2011). Furthermore, the stress-buffering effects of parent support appear to decline during puberty, while the impact of friends' support on reducing physiological stress increases (Gunnar \& Hostinar, 2015; Skinner \& Zimmer-Gembeck, 2016). Friends are therefore a critical source of support in adolescence and may be perceived as having particular expertise when discussing friendship problems or schoolwork (Zimmer-Gembeck \& Skinner, 2011). Adolescents prefer to seek support for interpersonal stressors from friends than from parents (Wilson et al., 2005), and also report seeking academic support from friends (Altermatt, 2007; Ryan \& Shim, 2012). This preference is particularly strong amongst adolescent girls (Altermatt, 2007; Boldero \& Fallon, 1995). While findings from focus group interviews 
with 15- and 16-year old adolescents indicate that emotional support may be the most valued type of support (Camara et al., 2017), informational and instrumental support are also likely to be salient and useful in academic contexts.

While there is a great deal of research focused on adolescent coping and support seeking, the relatively recent and rapid uptake of digital communication by adolescents represents a new context in which to consider adolescent support seeking. In support of this, a transformational framework has recently been proposed for considering how adolescent peer relationships are influenced by the digital psychosocial environment (Nesi et al., 2018). This model identifies that there are fundamental differences between in-person and digital communication that have the capacity to transform how adolescents behave and interact with each other. The aspects of digital communication that are likely to influence informal support seeking behaviours include the increased availability of friends, reduced social cues, time between digital exchanges (asynchronicity), and permanence of digital exchanges (Nesi et al., 2018). These differences have the potential to make digital support seeking more attractive to adolescents while also posing challenges for those who elect to seek emotional and academic support online.

\section{Why Might Adolescent Girls Use Digital Media to Seek Support?}

As adolescents show high levels of engagement with friends online (Anderson \& Jiang, 2018a; Reich et al., 2012), it follows that digital media devices may facilitate greater access to support from friends. As discussed in the previous section, friends are critical support providers for adolescents (Gunnar \& Hostinar, 2015), and increased referral to friends for support is a normative developmental process during the adolescent years (ZimmerGembeck \& Skinner, 2011). Digital media provides adolescents with potentially constant access to their friends regardless of their physical location (Spies Shapiro \& Margolin, 2014). This frequent access is likely to facilitate increased support seeking opportunities with friends. In addition, increased access to a wider range of support providers via digital media has been well-established by researchers focusing on health related emotional and informational support seeking (Rains \& Wright, 2016; Tanis, 2007). It follows that adolescents are also likely to have access to a greater variety of informal support providers online, such as friends from primary school or extracurricular activities (Manago et al., 2012).

While accessing support providers is an important reason for seeking support electronically, there are also perceived emotional benefits of seeking digital support. Many adolescents report finding that self-disclosure is easier online than in face-to-face contexts (Schouten et al., 2007). This view is supported by the hyperpersonal communication model, in which reduced social cues in electronic exchanges stimulate self-disclosure through an 'online disinhibition effect' (Rains et al., 2017; Suler, 2004; Walther et al., 2015). Increased self-disclosure in turn predicts having higher quality friendships (Valkenburg \& Peter, 2009). Some adolescents identify that online selfdisclosure protects them from feeling vulnerable when discussing their feelings, while the asynchronous nature of digital communication offers them more control over their expressions (Best et al., 2016; Nesi et al., 2018; Vermeulen et al., 2018a). Thus, for some adolescents, a perception of reduced interpersonal costs (Lim et al., 2013) or reduced stigma (DeAndrea, 2015) may facilitate digital support seeking. Notwithstanding these possible benefits, research also suggests several limitations may be associated with seeking support using digital media devices.

\section{Potential Limitations for Adolescent Girls Seeking Support Using Digital Media}

In contrast with the hyperpersonal communication model, the "cues-filtered-out" perspective suggests that the quality of digital communication is undermined by a lack of non-verbal cues (Walther et al., 2015). This has several possible implications for digital support seeking. One possibility is that the quality of support received electronically is poorer than that received in-person. For example, text-based support is devoid of facial expressions and physical gestures, which are often used to determine whether advice or feedback is genuine (Rains et al., 2017). In support of this possibility, Lewandowski and colleagues (2011) found that adults who received support in-person reported feeling more positive about the supportive interaction than those who received support via digital media. Furthermore, adolescents who used high levels of online emotional support seeking were found to experience increases in worry, jealousy, and loneliness (Duvenage et al., 2020). Similarly, Rains et al. (2017) found that college students who received support via IMing experienced higher levels of uncertainty and worry than those who received the same support in-person in an experimental study. Finally, in 
recent work by Vermeulen et al. (2018a), Flemish adolescents identified that they preferred to share emotions face-to-face rather than online. This was because they could see the reactions of their friends and clarify misunderstandings. Together, these findings support the notion that the quality of digital support is undermined by reduced social cues.

Another potential implication of the cues-filtered-out perspective for digital support seeking is that reduced social cues in online exchanges - although useful for self-disclosure - can lead to a toxic disinhibition effect: specifically, peers may be more critical online than they would be in-person (Koutamanis et al., 2015; Suler, 2004). Indeed, some adolescents report receiving negative feedback online, which can be particularly problematic due to the public and permanent nature of online feedback (Nesi et al., 2018; Valkenburg et al., 2006). Negative online support and feedback are in turn related to decreases in self-esteem and poorer mental health (McCloskey et al., 2015; Valkenburg et al., 2006). While there has been significant research attention on adolescents' negative online peer interactions in the context of cyberbullying (e.g. Patterson et al., 2017; Spears et al., 2015) and conflict or 'drama' (e.g. Ging \& O'Higgins Norman, 2016; Pabian et al., 2018), it is unclear whether receiving negative feedback in response to digital support seeking attempts is viewed as a limitation by adolescent girls.

Finally, adolescents report that their ability to trust their support provider is important in their decision to seek support in-person (Camara et al., 2017). This trust may be more difficult to establish in digital contexts, however. An important difference between in-person and digital interactions is that digital platforms automatically record conversations, which can then be accessed after the original interaction (Peter \& Valkenburg, 2013). While the permanent nature of online communication has been raised as problematic for adolescents in the case of uploading inappropriate content (e.g. Cooper et al., 2016; Nesi et al., 2018), adolescents may also be concerned about their support seeking attempts being shared with others. Indeed, the potential for disclosure of personal information to unintended others has been identified as a salient concern by adolescents in several studies (Best et al., 2016; Vermeulen et al., 2018a). It is unknown, however, whether trust concerns influence adolescent girls' digital support seeking behaviours.

\section{Study Context}

This study explored the perceptions and experiences of early and middle adolescent girls in Australia. While the experience of everyday stress is normative across the lifespan, the early to middle adolescent period is a particularly stressful time (Seiffge-Krenke, 1995). During this period, adolescents nominate concerns about family and peer relationships, academic concerns, and societal issues as major causes of stress (Frydenberg, 2008). In Australia, early adolescents must also navigate a major school transition from primary to secondary school, with common transition stressors including increased academic pressure, the need to learn new school routines, and the need to make new friends (Waters et al., 2014). As support seeking is a commonly used way of coping with stress (Zimmer-Gembeck \& Skinner, 2011), it is particularly important to investigate adolescents' experiences when seeking support from friends in relatively new digital contexts.

The study population was drawn from four socioeconomically advantaged schools, as part of a larger study of support seeking behaviours and mental health in adolescent girls. Findings regarding the association between socioeconomic status and mental health in adolescence are equivocal, with some studies finding that adolescents from low socioeconomic backgrounds are more likely to experience mental health problems (Lawrence et al., 2015; Reiss, 2013), and some finding no difference (Avenevoli et al., 2014). Surprisingly, then, there are also concerns about adolescents who attend affluent schools, as research suggests that adolescents who attend affluent schools exhibit problematic levels of maladjustment (Luthar \& Barkin, 2012). For example, girls attending such schools appear to be more likely to experience risk factors for later internalising problems, such as body dissatisfaction and peer envy (Lyman \& Luthar, 2014). As such, scholars emphasise the role of achievement pressure in increasing the vulnerability of adolescents from affluent schools (Luthar \& Kumar, 2018). Indeed, girls from advantaged socioeconomic backgrounds report experiencing high levels of stress, driven by intense pressure from themselves and others to succeed (Spencer et al., 2018). As girls commonly use support seeking to cope with stress (Eschenbeck et al., 2007), and report doing so electronically (Anderson \& Jiang, 2018a; Bullot et al., 2017), this was a particularly important population in which to examine digital support seeking behaviours. 


\section{Study Purpose}

Informal digital support seeking may represent an important, and relatively new way in which adolescents cope with stress. The research reviewed in the preceding sections indicates that there are several potential benefits and limitations of digital support seeking for adolescent girls, but early and middle adolescent girls' reasons for seeking support from their friends using digital devices, and their perceptions of benefits or limitations of digital support seeking have received minimal research focus to date. An understanding of these reasons and perceptions is critical to identifying specific digital support seeking behaviours that may be useful or problematic for adolescent girls. As such, the current study investigated: (i) frequency of digital support seeking for academic and emotional support from friends, (ii) preferences for digital or in-person support seeking, and (iii) girls' perceptions of the benefits and limitations of digital support seeking from friends. We focused on text-based forms of digital support (rather than video chat platforms), as these are the most distinct from face-to-face support due to the reduced social cues available in text-based environments. Given that adolescents have previously identified that emotional support is their most valued type of support (Camara et al., 2017) and that academic concerns are highly salient (Spencer et al., 2018), we also narrowed our focus to emotional and academic support seeking from friends. These are also areas in which peers may be perceived to have particular expertise or share common experiences. While we employed a mixed-method design, the current study is largely focused on the qualitative data to generate a deep understanding (Smith, 2015) of adolescent girls' use of digital support seeking.

\section{Method}

\section{Participants}

Participants were 186 girls ( $M_{\text {age }}=13.64, S D=1.03$, range $=10.29-15.33$ years) in Grades 7 and 9, drawn from four Independent Girls' Schools in Sydney, Australia in 2015. Girls in Grades 7 and 9 were targeted to represent early and middle adolescents. All four schools were high-fee schools, and girls were at relative socioeconomic advantage in comparison to other students in Australia (Australian Curriculum, Assessment, and Reporting Authority, 2015). On average, $41.5 \%$ of students in these four schools had a language background other than English. While this appears to be a high proportion of students, it is indicative of the typical level of cultural diversity in the Sydney urban area, where 38.3\% of households have a language background other than English (Australian Bureau of Statistics, 2011). Importantly, linguistic diversity is not a marker of low socioeconomic status in the current context.

The overall response rates for the questionnaire were $21.20 \%$ for Grade 7 and 30.59\% for Grade 9. Interview participants were selected from a pool of participants who had ticked a response option on the consent form agreeing to participate in follow up interview (67.96\% of the questionnaire participants). Five girls who were contacted to participate in the interview subsequently opted out of the interview. Interviews were conducted until a data saturation point was reached and no new responses to questions were apparent (Saunders et al., 2018). The final interview sample included 14 girls in Grade 7 and 17 girls in Grade 9, who reported varying frequencies of digital support seeking in their questionnaire responses.

\section{Materials and Procedure}

\section{Questionnaire}

Following approval by the institutional ethics committee and school principals, students were invited to participate in a larger study of adolescent girls' support seeking preferences, digital communication practices, and wellbeing. Consent forms were distributed to students and their parents, which invited potential participants to complete a 40-minute questionnaire during a nominated class period at school and an optional follow up interview outside school hours. Students who provided written parental and student consent $(N=186)$ completed the paper-based questionnaire, which was administered by the first author.

To determine the frequency of adolescent girls' digital support seeking and communication, the questionnaire asked participants how often they used digital media to: (a) chat to friends, (b) seek academic support, and (c) seek emotional support from friends. Frequency was reported on a 6-point Likert scale where $1=$ not at all and $6=$ several times a day. Participants were also given a list of ten commonly used digital media tools (e.g. social media 
platforms, text messaging, email) from which they could identify the tools that they used to communicate generally with their friends, using a yes or no response option. There was also a free response option for participants to add any other digital media tools to the list. There was no missing data from the questionnaire items. One participant selected two frequency responses for two items, and the average of these responses was recorded for each item.

\section{Interviews}

To determine adolescent girls' attitudes and experiences of digital support seeking, a representative subsample of 31 girls completed a one-on-one semi-structured interview. Girls were selected because they had varying frequencies of digital support seeking, from low (once per week or less) to high (once per day or more). Girls who did not use digital support seeking at all were excluded, as the focus of the interviews was on adolescents' perceptions and experiences when seeking digital support. Girls were included if they reported seeking only one type of support (academic or emotional), however. All girls gave verbal consent before the interview began.

The interviews were conducted by the first author over phone at a time convenient to the adolescent outside school hours. Interviews took between 10 and 20 minutes, which was appropriate given our relatively narrow focus on a specific online behaviour. The first author also conducted the surveys in schools before the interviews and, as such, spent time establishing rapport with participants prior to the interviews beginning. Interviews were audio recorded, and transcribed verbatim. To retain participants' candid responses to questions, and to minimise the time requirement for participants, transcripts were not returned to participants for checking (Hagens et al., 2009).

At the beginning of each interview, the interviewer identified that the focus of the interview was on how people use technology to ask for help, advice, and emotional support. As the typical adolescent uses a range of digital communication tools (Anderson \& Jiang, 2018b), we made the scope of digital media very broad by defining technology as social media, text messaging, apps, and instant messaging. Participants were asked about the types of problems or issues they sought support for from their friends using digital media (e.g. "Are there some things that you feel more comfortable talking to your friends about online rather than in-person?"), the modes of support seeking they most preferred, and why (e.g. Are there other problems or issues that you prefer to talk to your friends about in-person? Why?). They were also asked about any problems or difficulties that they had experienced when seeking support using digital media (e.g. "Are there any problems or bad experiences that you have had with asking for support online?").

\section{Interview Analysis}

As our aim was to explore adolescent girls' experiences and perspectives of online support seeking, we used inductive analysis to allow themes to be driven by the data (Thomas, 2006). The first author generated an initial coding scheme based on analysis of all transcripts using a general inductive approach. During this process, field notes taken during the interviews were combined with repetitive reading of the transcripts to ensure participants' meanings were adequately captured by the coding scheme (Braun \& Clarke, 2012). Codes were initially developed through holistic reading of the transcripts, followed by comparing similar segments of text to refine codes. In some cases, participants' responses to particular questions were compared, for example, in examining the types of problems they preferred to discuss online or in-person. Similar codes were then merged into themes (Clarke, Braun, \& Hayfield, 2015). The second author checked the reliability of the coding scheme by independently coding $54.8 \%(n=17)$ of the transcripts using the initial coding scheme developed by the first author. This resulted in a pooled Cohen's kappa value of 0.69. Differences in the application of the codes were then discussed and modified. In cases where disagreement about the application of codes existed, we initially reviewed the definition of the code in question. If disagreement remained, both coders reviewed the transcript to clarify the meaning of the response in light of the remainder of the interview responses and a resolution for the application of the code was negotiated. Codes that were overlapping or closely related were merged or dropped (Campbell et al., 2013) until $100 \%$ agreement was achieved for each code. Once the reliability of the coding scheme was confirmed, the first author applied this coding scheme to the analysis of the remaining transcripts. Codes were identified as representing subthemes, which were then grouped into broader themes. The grouping of subthemes into themes was discussed and agreed upon by the two coders. 


\section{Results}

\section{Frequency of Digital Support Seeking}

To determine the frequency of digital support seeking and communication amongst the adolescent girls we drew on the questionnaire responses. To help contextualise our subsequent interview analyses, we also provide a comparison of questionnaire responses between the sub-sample interviewed and the larger study sample. In particular, we note that the frequency of digital communication and support seeking was naturally higher in the interviewed subsample because of the exclusion of those who did not seek support using digital media. Digital communication and support seeking were both prevalent. Over half (58.06\%) communicated with their friends online daily or multiple times per day, using up to 11 different digital media tools (see Table 1). Text/iMessages were the most commonly used communication tool, followed by Instagram, Snapchat, Kik, and Facebook. Most girls sought both academic support (85.48\%) and emotional support (73.66\%) using digital media; however, frequencies varied. On average, digital media was used to seek academic support once per week and emotional support less than once per week. A small proportion of girls reported daily seeking of academic support (13.98\%) and emotional support (10.22\%) using digital media (Table 1).

Table 1. Digital Behaviours of Whole Study and Interview Participants.

\begin{tabular}{|c|c|c|c|c|}
\hline \multirow{2}{*}{ Digital communication use variables } & \multicolumn{2}{|c|}{ Entire Study Sample $(N=186)$} & \multicolumn{2}{|c|}{ Interview Sample $(n=31)$} \\
\hline & $N$ & $\%$ & $n$ & $\%$ \\
\hline \multicolumn{5}{|c|}{ Number of digital communication tools used } \\
\hline $1-3$ & 70 & 37.63 & 12 & 38.71 \\
\hline $4-6$ & 96 & 51.61 & 15 & 48.39 \\
\hline $7-9$ & 15 & 8.06 & 3 & 9.68 \\
\hline $10+$ & 3 & 1.61 & 1 & 3.23 \\
\hline \multicolumn{5}{|l|}{ Digital communication tools used } \\
\hline Text/iMessage* & 177 & 95.16 & 29 & 93.55 \\
\hline Instagram & 132 & 70.97 & 21 & 67.74 \\
\hline Snapchat & 125 & 67.20 & 20 & 64.52 \\
\hline Facebook & 59 & 31.72 & 12 & 38.71 \\
\hline Kik & 78 & 41.94 & 11 & 35.48 \\
\hline \multicolumn{5}{|c|}{ Frequency of chatting to friends using digital media^ } \\
\hline Not at all & 9 & 4.84 & 1 & 3.23 \\
\hline Less than once a week & 21 & 11.29 & 2 & 6.45 \\
\hline Once a week & 14 & 7.53 & 1 & 3.23 \\
\hline Once every $2-3$ days & 34 & 18.28 & 4 & 12.90 \\
\hline Once a day or more & 108 & 58.06 & 23 & 74.19 \\
\hline \multicolumn{5}{|c|}{ Frequency of seeking academic support using digital media^ } \\
\hline Not at all & 27 & 14.52 & 4 & 12.90 \\
\hline Less than once a week & 55 & 29.57 & 6 & 19.35 \\
\hline Once a week & 31 & 16.67 & 7 & 22.58 \\
\hline Once every $2-3$ days & 47 & 25.27 & 7 & 22.58 \\
\hline Once a day or more & 26 & 13.98 & 7 & 22.58 \\
\hline \multicolumn{5}{|c|}{ Frequency of seeking emotional support using digital media^ } \\
\hline Not at all & 49 & 26.34 & 6 & 19.35 \\
\hline Less than once a week & 75 & 40.32 & 9 & 29.03 \\
\hline Once a week & 27 & 14.52 & 4 & 12.90 \\
\hline Once every $2-3$ days & 16 & 8.60 & 3 & 9.68 \\
\hline Once a day or more & 19 & 10.22 & 9 & 29.03 \\
\hline
\end{tabular}

\section{Attitudes and Perceptions Towards Digital Support Seeking}

The following sections will explore girls' attitudes and perceptions towards digital support seeking using interview data. While our interviews were focused on digital support seeking from friends, we also asked the girls to identify whether they had sought support from any other exclusively online contacts. Three girls reported that they had sought support from someone unknown to them personally in offline or face-to-face contexts. This suggests that 
most girls restricted their support seeking using digital media to people that they knew in-person (i.e. friends, peers, or family).

\section{Attitudes Towards Digital Academic Support}

Most girls in the interview sample - 27 of 31 - sought academic support using digital devices. Unsurprisingly, academic support seeking was also a key theme that emerged throughout the interviews. Girls identified several academic issues that resulted in them seeking digital academic support, including experiencing difficulties with homework or assignments, misunderstanding task requirements, and missing work when absent from school. The ability to seek academic support from friends for these issues was almost universally perceived as a beneficial aspect of digital support. Specific benefits included increased understanding (e.g. "If I didn't understand the question they would help me answer it properly" (Ava, Grade 9) and information about homework requirements (e.g. "I'll ask my friends some little things about homework" (Kate, Grade 7). Some girls identified that their friends provided expedited or easy homework assistance: "It's easier to just text them and ask them what's this answer, or can I have help with this question" (Jackie, Grade 7). Others sought support electronically from friends to catch up on material they may have missed: "asking about what work I missed out on at school" (Amelia, Grade 9). Many girls' accounts of digital academic support seeking also identified the immediacy of support as a key benefit:

"If I'm having trouble [with homework] I'll just message my friends... I can just message them straight away and they'll normally get back to me within 5 minutes, so that can be really helpful." (Alexa, Grade 9)

These girls perceived that online support seeking provided valued academic assistance, with only one girl discussing a negative response from friends when seeking academic support:

"Like, sometimes you ask them 'oh, what did you get for this answer?' and they go off because they don't really want to tell you... then you can be angry at your friends, but maybe you can understand, and you can be careful what you ask." (Emma, Grade 7)

There were no references to seeking emotional support in relation to academic issues throughout the interviews. This suggests that the girls only sought instrumental and informational support for academic concerns.

\section{Preferred Mode of Seeking Emotional Support}

While the ability to seek academic support was almost universally perceived as a benefit of digital support seeking, opinions about the use of digital devices for emotional support were quite varied within the interview sample. Analysis of the interview responses revealed that there were four groups of girls with distinct overall attitudes towards digital and in-person emotional support seeking. Group $1(n=12)$ demonstrated a strong preference for seeking emotional support in-person and avoided seeking emotional support electronically. In contrast, Group 2 $(n=11)$ preferred seeking emotional support in-person but would seek emotional support electronically when they were physically separated from their friends. These girls tended to view digital support seeking as a back-up support seeking option, rather than their preferred method. Group 3 were distinctive, as they preferred to seek emotional support online for specific types of problems $(n=6)$. These problems tended to be embarrassing or awkward, or issues that caused them to display negative emotions. They also indicated they would use both inperson and digital emotional support for less emotionally charged problems. Finally, Group $4(n=2)$ identified that they did not consider in-person and digital platforms to be distinct modes for seeking support, and that they would discuss the same issues in either mode. No clear age differences were apparent within the groups: the numbers of early and middle adolescents in each of the first three groups were approximately equal. While the two members in Group 4 were middle adolescents, we recommend against drawing any conclusions about this finding given the small size of this group. 
Perceived Benefits and Limitations of Seeking Emotional Support Electronically

Table 2. Summary of Themes and Subthemes Identified in Girls' Reasons for Seeking Emotional Support Using Digital Media.

\begin{tabular}{|c|c|c|c|}
\hline \multirow{2}{*}{ Theme } & \multirow{2}{*}{ Sub-theme } & \multicolumn{2}{|c|}{ Example quote } \\
\hline & & Perceived benefit & Limitation \\
\hline \multirow[t]{3}{*}{$\begin{array}{l}\text { Emotion } \\
\text { regulation }\end{array}$} & $\begin{array}{l}\text { Reduced regulation } \\
\text { of emotion online }\end{array}$ & $\begin{array}{l}\text { You feel like you can say pretty much } \\
\text { anything you want [online] but in real } \\
\text { life you have to be more careful about } \\
\text { what you say (Charlotte, Grade 9, } \\
\text { Group 3) }\end{array}$ & $\begin{array}{l}\text { Because you keep talking about it you get more } \\
\text { angry (Tara, Grade 7, Group 3) }\end{array}$ \\
\hline & $\begin{array}{l}\text { Avoidance of in- } \\
\text { person emotional } \\
\text { displays }\end{array}$ & $\begin{array}{l}\text { Your friends don't really have to see } \\
\text { you getting emotional [online] } \\
\text { (Stephanie, Grade 9, Group 3) }\end{array}$ & $\mathrm{n} / \mathrm{a}$ \\
\hline & $\begin{array}{l}\text { Coping with } \\
\text { emotion }\end{array}$ & $\begin{array}{l}\text { Like especially if I've had a bad day they } \\
\text { say everything will be ok, and that } \\
\text { makes me feel better (Anna, Grade 9, } \\
\text { Group 1) }\end{array}$ & $\begin{array}{l}\text { Not as good as I would feel if I was talking to them } \\
\text { face-to-face (Jane, Grade 7, Group 2) }\end{array}$ \\
\hline \multirow[t]{4}{*}{$\begin{array}{l}\text { Friendship } \\
\text { experiences and } \\
\text { expectations }\end{array}$} & $\begin{array}{l}\text { Digital self- } \\
\text { disclosure in } \\
\text { friendships }\end{array}$ & $\begin{array}{l}\text { I find that like in some situations it } \\
\text { [online] could be easier if you're not } \\
\text { really sure how to express your feelings } \\
\text { (Molly, Grade 7, Group 3) }\end{array}$ & $\begin{array}{l}\text { [in-person] you can just explain what you need } \\
\text { better, and um it's just a lot easier to talk about it } \\
\text { (Mia, Grade 9, Group 1) }\end{array}$ \\
\hline & $\begin{array}{l}\text { Trust in digital } \\
\text { interactions }\end{array}$ & $\begin{array}{l}\text { Online it's like "oh I can tell this person } \\
\text { something and I trust them" (Charlotte, } \\
\text { Grade 9, Group 3) }\end{array}$ & $\begin{array}{l}\text { I'd rather speak to them face-to-face, because they } \\
\text { can screenshot it [online exchanges] (Sophia, } \\
\text { Grade 7, Group 1) }\end{array}$ \\
\hline & $\begin{array}{l}\text { Expectation of } \\
\text { support }\end{array}$ & $\begin{array}{l}\text { If you need something, say on a } \\
\text { weekend, you can text them and they } \\
\text { can help you straight away (Abbey, } \\
\text { Grade 7, Group 2) }\end{array}$ & $\mathrm{n} / \mathrm{a}$ \\
\hline & $\begin{array}{l}\text { Effect of digital } \\
\text { support seeking on } \\
\text { friendship strength }\end{array}$ & $\begin{array}{l}\text { If anything it kinda brings us closer... it } \\
\text { helps us understand each other and } \\
\text { what we need help with (Lucy, Grade 9, } \\
\text { Group 4) }\end{array}$ & $\begin{array}{l}\text { They'd get awkward, like "why didn't you just do it } \\
\text { to my face?" (Alexa, Grade 9, Group 1) }\end{array}$ \\
\hline $\begin{array}{l}\text { Quality of digital } \\
\text { support }\end{array}$ & & $\begin{array}{l}\text { They tell me if I need any advice, so it } \\
\text { really helps (Ella, Grade 7, Group 3) }\end{array}$ & $\begin{array}{l}\text { You can't see their facial expression, you can't give } \\
\text { them hugs and stuff... so I think in-person is better } \\
\text { than online (Maddie, Grade 9, Group 2) }\end{array}$ \\
\hline
\end{tabular}

Across the interviews, we coded participants' explanations for why they sought emotional support using digital media (benefits) and about any problems or difficulties they had encountered (limitations). Three specific themes emerged (see Table 2), each of which are described below. Most interviewees (80.65\%) experienced emotional support after seeking support electronically, and identified specific benefits of digital support seeking including access to friends and emotion regulation. Similarly, most interviewees also recognised significant limitations in the quality of emotional support (83.87\%). Almost one-third (29.03\%) had received negative feedback or did not feel supported following a request for support. Similar themes emerged from the groups identified in the previous section, with several notable exceptions that are identified below. Each quote presented in the following sections is accompanied by the participants' pseudonym, grade, and their overall emotional support seeking preference (Group 1-4).

\section{Emotion Regulation}

Emotion regulation was the most significant theme to emerge across all interview accounts, with 19 of the 31 girls (64.52\%) reporting the use of digital support seeking to manage, express, and regulate their emotions. The key benefit perceived by some girls was a perception that they did not have to regulate their emotional expression in digital contexts and could be more disinhibited in their expressions: "You can talk to people without facing consequences of what you say right there" (Sarah, Grade 9, Group 3).

One explanation that girls gave for this perception was that they felt less embarrassed expressing their emotions electronically: "If it's something one-on-one that you want to talk to a friend about you'll probably just text them, because it's less embarrassing" (Maddie, Grade 9, Group 2). They were also less threatened by the potential to receive negative reactions from their friends, and were therefore able to avoid feeling bad themselves by "switching off straight away" (Lara, Grade 9, Group 2). In contrast to the girls who discussed the possibility of 
disinhibition, others specifically discussed the potential to monitor, mask, or otherwise control their emotional displays: "I might prefer to talk online if I didn't want to be really emotional but I still wanted to talk to somebody" (Molly, Grade 7, Group 3). These affordances of digital support seeking were only endorsed by girls in Groups 2 and 3, with no girls in Group 1 or 4 identifying that digital support seeking allowed them to regulate emotions or avoid emotional displays. As girls in Group 1 reported a strong preference for seeking emotional support inperson, it is possible that these girls felt comfortable expressing their emotions in-person, or that they were able to regulate their emotions in face-to-face exchanges.

Some girls reported greater emotional wellbeing (e.g. reduced stress and anger) after receiving support electronically. For these girls, discussing problems with friends electronically increased their ability to cope with these problems. Friends gave advice that reduced feelings of stress and anger, provided distraction, and were viewed as important partners in working through concerns to achieve emotional relief: "Just talking to my friends [online] usually makes me feel better than just thinking about things alone" (Michelle, Grade 9, Group 2). While some girls identified face-to-face support as more effective in reducing negative emotions than digital support, digital support seeking was still useful when their friends were unavailable in-person: "Sometimes just letting it out even if it's online it makes you feel better, but I still think I prefer to do it in-person" (Hailey, Grade 9, Group 2). For these girls, digital support seeking served as an additional avenue through which they could seek emotional support and was used alongside in-person support.

\section{Friendship Experiences and Expectations}

Expectations of friendship were frequently raised as benefits and limitations in girls' reports of digital support seeking. An expectation of trust in electronic exchanges between friends was raised by over half (51.61\%) of the girls during the interviews. Only two reported that they felt that their friends were honest and trustworthy in electronic exchanges. The remaining fourteen girls reported some level of concern about their ability to trust their friends, mainly because their personal conversations could be easily shared with others, particularly if a friendship turned sour: "I trust them but like, you never know when they might turn on you and use things against you" (Ivy, Grade 9, Group 2).

Of the girls who identified concerns about trusting their friends in online exchanges, a key concern was that the text-based nature of digital communication meant that their exchanges could be used as evidence against them: "There's been times where people have told other people, because it's so easy to screenshot it and forward it to other people" (Alexa, Grade 9, Group 1). Trust concerns also left some adolescents cautious about the advice their friends provided electronically: "You don't know their facial expressions... you just know that they're typing something, but it could not be the truth" (Emma, Grade 7, Group 1).

Girls reactions to trust concerns varied. Girls with trust concerns in Groups 2 and 3 reported carefully editing their digital expressions, for example: "Sometimes I feel worried that something I'll say that's personal to me will possibly be shared... it's made me think more about the words that I use" (Stephanie, Grade 9, Group 3). In contrast, girls in Group 1 tended to avoid talking about personal issues entirely: "I won't really talk about problems by text, because then they can copy it" (Leah, Grade 7, Group 1), and identified that they preferred to discuss personal problems in-person: "I feel more comfortable talking in-person, cause no one's hearing if you're having a private conversation" (Fiona, Grade 7, Group 1). Given trust concerns were raised by all but two girls in Group 1, it appears that not being able to trust friends in online exchanges was a major barrier preventing these girls from seeking emotional support electronically.

Self-disclosure of problems and emotions to friends was raised by approximately half of the girls in the interviews. More girls $(n=11 ; 35.48 \%)$ viewed digital platforms as a limitation to self-disclosure in their friendships, or being less effective than in-person opportunities: "It's easier to express your emotions when you're actually in [face-toface] contact with the person" (Michelle, Grade 9, Group 2). Some were concerned about miscommunication in electronic exchanges: "People can take things the wrong way on social media" (Alexa, Grade 9, Group 1). In contrast, seven girls reported that digital platforms provided opportunities for enhanced self-disclosure, both because they had additional time to control and construct emotional responses and because they were more comfortable communicating difficult emotions electronically: "I don't have to build up as much strength to 
message someone and ask for help" (Stephanie, Grade 9, Group 3). The girls who felt that self-disclosure was easier online were distributed across Groups 2 and 3, and no girls in Group 1 or 4 shared this view.

Expectations of immediate support were discussed by nine (29.03\%) girls. These girls expected their friends to provide immediate emotional and academic support whenever required: "It's an immediate response, and you can talk about it straight away rather than waiting until the next day" (Maddie, Grade 9, Group 2). The knowledge that their friends could be relied on to offer support was reassuring for some of these girls: "If we're ever in need of help, you can rely on them and they'll reply back" (Jackie, Grade 7, Group 1).

Some girls reported that digital support seeking had strengthened their relationships with their friends, because they were able to communicate with their friends more frequently:

"You become more close with your friends, because you can talk to them more often, and they can help solve your problems a lot more." (Rachel, Grade 9, Group 2)

For the girls who felt self-disclosure was easier online, digital support seeking enabled them to ask their friends for help, which they perceived as having a strengthening effect on their relationship. In contrast, others identified that seeking support from friends electronically made their relationships seem weaker:

"It makes it seem like you're not as close as you think you are, because if you were really close friends, then you obviously just feel comfortable asking them to their face." (Hailey, Grade 9, Group 2)

For these girls, being able to discuss their problems with friends in-person was indicative of a strong friendship. Unsurprisingly, these girls also shared the view that self-disclosure was more difficult via digital platforms, indicating an overall preference for in-person support.

\section{Quality of Digital Support}

The final theme emerging from our interviews related to the quality of digital support. Girls expressed distinct opinions about the quality of digital support: while some considered digital support as being equivalent to the support they would receive from their friends in-person, others viewed digital support as being poorer in quality. Benefits of digital support seeking included being able to obtain positive support or advice (e.g. "I've normally had positive or nice comments" (Jackie, Grade 7, Group 1)), gain friends' perspectives on their problems (e.g. "It helps me get another viewpoint" (Michelle, Grade 9, Group 2)), and giving friends time to think about their reply before giving advice:

"The person has time to think about their reply... they can say what they know will make you happier." (Charlotte, Grade 9, Group 3)

For over half the girls interviewed $(n=18,58.06 \%)$, however, the quality of the support provided electronically was limited. Reduced social cues and inability to see physical responses reduced the emotional comfort that could be provided by either party:

"I think I'd be better talking to somebody face-to-face so that they can actually help me. They'd be able to comfort me in a way that text wouldn't really do anything for. It's just words instead of actual feelings." (Lara, Grade 9, Group 2)

In-person support seeking was viewed as more effective for complicated problems: "If you need a lot of help they can go through it with you [in-person]" (Mia, Grade 9, Group 1), or when they preferred parental input: "My parents' advice is more experienced" (Tara, Grade 7, Group 3). Consistent with these perceived limitations, girls reported specific instances of poor-quality advice in response to digital support seeking attempts:

“I thought these people would be able to understand me, but they didn't so I felt really let down... [If it were in-person] I think they would have thought more about what they were saying and how that would affect me emotionally." (Stephanie, Grade 9, Group 3) 
"I remember one time I was talking to my friend [online] about this girl who was being really mean to me, and she's like 'oh I don't think she meant it'. If she heard what my voice had sounded like, I was really upset." (Sophia, Grade 7, Group 1)

These girls recognised that the reduction of social cues in digital exchanges left their friends unable to recognise the severity of their problems, leaving them feeling unsupported after attempting to seek support. The view that digital support seeking was poorer in quality than face-to-face support was shared by girls in all groups. While this is unsurprising for those who avoided seeking emotional support online (Group 1), it did not stop the girls in Groups 2, 3, and 4 from using digital support. This suggests that some girls were prepared to accept poorer quality support due to the other affordances of digital support seeking (e.g. being able to access friends when physically separated or finding self-disclosure easier online).

\section{Discussion}

This study was designed to assess relatively unexplored aspects of adolescent digital support seeking. Building on prior research suggesting that adolescent girls engage in both digital and in-person support seeking, the first goal of this study was to identify the frequency with which girls report seeking informal support electronically. Second, this study aimed to investigate adolescent girls' preferences for digital or in-person modes of support seeking. The final goal of this study was to explore girls' explanations of the benefits and limitations of digital support seeking.

\section{Frequency of Digital Support Seeking}

First, the results demonstrate that digital support seeking was a common feature in the life of most early to middle adolescent girls in this sample, reflecting girls' preferences for seeking support from friends to cope with daily stress (Eschenbeck et al., 2007). For most, however, digital support seeking was not a daily occurrence despite many communicating electronically with friends on a daily basis. This suggests that girls may employ other ways of coping with daily hassles or continue to rely on in-person support seeking at the same time as engaging electronically. A small percentage of girls were more heavily reliant on digital support seeking (13.98\% for academic stressors and $10.22 \%$ for emotional support) and reported doing so daily or multiple times per day. It is possible that adolescents who seek support online frequently require higher levels of support, as has been found in a longitudinal study of adults (Utz \& Breur, 2017). Alternatively, these adolescents also may not have had access to the support they require in-person. Indeed, several studies have reported that online support is particularly beneficial for adolescents with poorer quality friendships and adolescents experiencing depression, with hypothesised benefits including reduced social isolation and increased capacity to connect with similar others (Radovic et al., 2017; Selfhout et al., 2009). As frequent digital emotional support seeking has been found to be associated with more negative short-term responses to stress in adolescents (Duvenage et al., 2020), determining the long-term outcomes of frequent use of digital support seeking will be an important focus for future research.

\section{Preferred Mode of Support Seeking}

The second goal of this study was to identify adolescent girls' preferred mode of support seeking. Analysis of the interview data revealed four groups of girls with distinct preferences for the way in which they sought emotional support. The two largest groups (representing two-thirds of the interview sample) shared an overall preference for seeking support in-person rather than electronically. Recent research has found that while 15- to 17-year-old adolescents' most preferred mode of communicating with friends is by text message, 13- to 14-year-olds prefer to communicate with friends in-person (Rideout \& Robb, 2018). Thus, it is possible that this finding reflects the preferences of younger adolescents for communicating with their friends in-person rather than by text. However, given the limitations of online support identified by the girls in this study, this preference for in-person sources of support suggests that adolescents recognise clear benefits of seeking support in-person (Frison \& Eggermont, 2015; Vermeulen et al., 2018a). The preference for seeking support in-person also aligns with the preferences of college students, who are more likely to seek support in-person rather than by text message or online (Rife et al., 2016) and identify that in-person exchanges are more supportive than those received via text-messaging or social media (Bayer et al., 2016). 
While the majority of girls displayed an overall preference for seeking emotional support in-person, there were two smaller groups of girls who did not share this preference. Both of these groups used a combination of inperson and digital emotional support, but Group 3 identified that they preferred digital emotional support for embarrassing or emotion-inducing problems and Group 4 felt that in-person and digital support were equivalent modes of support seeking. As identified in the following discussion, these groups of girls tended to have attitudes towards digital support seeking that could be a cause for concern (for example, use of digital support to avoid emotional displays). While further research is needed, the existence of groups of girls with distinct attitudes towards digital support seeking suggests that there are opportunities for future intervention efforts to target specific groups to more effectively support girls' coping behaviour.

When adolescent girls in this study did seek support electronically, our interview data suggests that they were most likely to engage with existing friends. Relatively few sought support from people they only knew online. This finding aligns with previous work that shows that adolescents mostly communicate with their existing friends electronically (Reich et al., 2012; Underwood et al., 2015). The ability to maintain contact and seek support from friends that girls couldn't see in-person regularly was also noted as an affordance of digital support seeking. Studies with college students have similarly identified the ability to maintain contact with past friends as an important affordance of SNSs (Ellison et al., 2007; Manago et al., 2012), and our findings suggest that some adolescent girls also use digital devices to seek support from wider networks of peers.

\section{Affordances and Limitations of Digital Support Seeking}

The final goal of this study was to investigate girls' own explanations of the benefits and limitations of digital support seeking. The most common affordance that girls identified was that digital platforms enabled them to obtain informational or instrumental academic support from friends. This finding extends previous research that has shown adolescents turn to peers when faced with academic difficulties (Altermatt, 2007; Ryan \& Shim, 2012), and supports the notion that academic stressors are particularly salient for adolescents in affluent schools (Spencer et al., 2018). As friends are often perceived as having expertise with schoolwork, the use of digital devices to access academic support from friends may also be interpreted as an example of adolescents' increasing capacity to match coping responses with particular stressors (Zimmer-Gembeck \& Skinner, 2011). In the case of homework, digital support seeking allowed them to access help immediately without needing to wait until the next class. A small group of adolescents reported more problematic help seeking, whereby they simply asked for answers to homework rather than for assistance to solve problems. This "expedient help seeking" (Kiefer \& Shim, 2016) is related to poorer academic achievement over time (Ryan \& Shim, 2012), and may be more common in digital settings where adolescents indicate a preference for the immediacy of help. Together, these findings suggest that digital academic help seeking is an important area of future research, with unknown implications for academic functioning. While it is possible that adolescents could benefit from some forms of digital academic help seeking (e.g. asking for more information about homework), there are others (e.g. expedient help seeking and referring to peers as soon as a problem with homework in encountered) that may have negative implications for academic functioning.

Girls identified that friends were expected to provide support whenever it was required, and the availability of immediate academic or emotional support was perceived as a key benefit of digital support seeking. While immediate access to informal support may be beneficial in many circumstances, several concerns have been raised in previous research on adolescents' use of digital communication (Nesi et al., 2018). For example, constant contact with friends and parents may have negative implications for adolescents' development of autonomy and emotion regulation (Davis, 2012; Spies Shapiro \& Margolin, 2014). While further research is needed, it is possible that expecting and receiving support as soon as a minor problem is presented could limit adolescents' capacity to independently solve problems or independently regulate their own emotions. This has the potential to have significant implications for the developmental progression of coping during middle adolescence, in which increased self-reliance in managing stressors is expected (Crystal et al., 2008; Skinner \& Zimmer-Gembeck, 2016). The continual need for support may also create an additional source of stress for the friends who are expected to provide support. Indeed, young people are reporting feeling burdened by others' expectations for replies to requests for help online (Calancie et al., 2017; Weinstein \& Selman, 2016). Future intervention efforts may consider how to support these friends who are providing support to others (Dudley et al., 2018). Finally, the increased access to support from friends that is afforded by digital communication has the potential to also increase 
exposure to negative aspects of social support, such as co-rumination (Davila et al., 2012; Nesi et al., 2018). Given the relatively well-established relationship between co-rumination and increased internalising symptoms in adolescents (Schwartz-Mette \& Rose, 2012; Stone et al., 2011), an important focus for future research will be to examine the relationship between digital support seeking and co-rumination in young adolescents.

It is also a concern that some of the limitations reported by adolescents suggest that electronic communication may undermine expectations of friendship. Many of the girls interviewed were concerned about their ability to trust their friends online, with the most common concern being that their friends would share private conversations with others. In response, some girls reported avoiding seeking emotional support electronically; others identified strategies such as carefully editing their electronic disclosures to minimise their risk. Concerns about friends sharing online disclosures have similarly been raised by Flemish adolescents as a reason for preferring to share emotions face-to-face rather than online (Vermeulen et al., 2018a). Some girls in our study also identified that reduced social cues made it difficult to determine the sincerity of the advice their friends provided electronically. These findings provide empirical support for digital communication transforming some aspects of adolescent girls' friendships (Nesi et al., 2018), and suggest that there may be some friendship-based challenges for girls to navigate when seeking support electronically.

A critical finding of this study was that some adolescent girls viewed digital support to have benefits for emotion regulation. These girls identified that digital support seeking allowed them to avoid sharing negative emotions (e.g. sadness, embarrassment) with friends in-person, and gave them control over how they discussed their emotions. This was particularly apparent in the third group, who preferred to seek digital support to avoid negative emotional displays or for embarrassing problems. This appears to be an example of the increasing development of "meta-emotions" in adolescence, whereby some adolescents may feel embarrassed about their emotions (Skinner \& Zimmer-Gembeck, 2016). As emotional suppression is associated with depression in adolescents (Betts et al., 2009), it seems that electronic communication may benefit adolescents who would otherwise not discuss their emotions in-person. It is also possible, however, that this highly controlled and selective sharing of emotions may carry negative implications by restricting the information that is provided to potential support providers. Furthermore, while there are benefits (e.g. support elicitation, increased relationship quality; Graham et al., 2008) and disadvantages (e.g. increased negative affect through rumination and venting; Choi \& Toma, 2014) of sharing negative emotions in general, it seems that sharing negative emotions online is more problematic than doing so in-person. For example, a recent study with college students found that sharing negative emotions electronically was related to greater increases in negative affect than sharing face-to-face (Choi \& Toma, 2014). The authors surmise that in-person support provides greater comfort to young people, which is also reflected in the perspectives of many girls in our study. Thus, while our study has identified that some adolescents may seek support electronically to avoid sharing negative emotions in-person, further research is needed to determine the implications of this support seeking behaviour for adolescent wellbeing.

Previous research has identified that online disinhibition can have both benefits (e.g. increased self-disclosure and relationship quality; Davis, 2012; Valkenburg \& Peter, 2009) and disadvantages (e.g. excessive meanness; White et al., 2018). Interestingly, the girls in this study were divided about whether self-disclosure was limited or enhanced by digital communication. Some girls (especially those in the first group) identified that self-disclosure was limited by digital platforms, and instead preferred to disclose their problems in-person. Conversely, other girls found it easier to discuss emotionally-charged or difficult problems online. We also found that some adolescents felt that they did not have to regulate their emotional expressions when seeking support online, because they could not be seen by their social partners. While it is likely that less inhibited self-disclosure will increase friendship quality (Valkenburg \& Peter, 2009), it is also possible that these unregulated expressions could manifest as over-sharing or inappropriate disclosures, thus leading to negative reactions from peers (High et al., 2014; Radovic et al., 2017). Thus, while online disinhibition has benefits and disadvantages for adolescent friendships in general, these variable effects also appear to extend to the specific context of digital support seeking.

Importantly, most adolescents were cognizant of the limitations of digital support seeking, as only two girls perceived digital and in-person support as being equivalent. Most perceived digital support as lower in quality than face-to-face support, which aligns with findings from previous studies with adult populations (Lewandowski et al., 2011; Trepte et al., 2015). In keeping with the cues-filtered-out perspective (Walther et al., 2015), reduced social cues and lack of physical contact limited the perceived quality of digital emotional support. The nature of 
the support or feedback itself was also problematic for some adolescents. While recent research suggests that perceptions of high online support confer important mental health benefits (Frison \& Eggermont, 2015), some adolescents did not always feel supported in the informal digital contexts investigated in this study. Given that many adolescents appear to be seeking support electronically, an important area of future research will be to determine factors that influence the quality of support received in digital contexts. Studies with young adult populations suggest that the tendency to provide support online is influenced by the degree of negativity in the support seeking attempt and whether support is sought in public or private digital spaces (High et al., 2014; Ziegele \& Reinecke, 2017). While our study did not investigate the specific platforms through which girls sought support, it is possible that the quality of support offered in digital contexts varies according to whether the request for help is made through private channels (e.g. IMing or text messaging) or through more public online spaces (e.g. Instagram or Facebook wall posts).

\section{Study Limitations}

While this study identifies patterns of digital support seeking amongst adolescent girls, there are several important limitations. First, and in line with our aim to investigate girls' digital support seeking behaviours, participants were purposively drawn from four Independent Girls' Schools in Sydney, Australia. In the Australian context, independent schooling suggests a relatively socioeconomically advantaged population. This may have influenced their reasons for seeking support, as research suggests that academic stressors may be amplified in such a population (Spencer et al., 2018; West \& Sweeting, 2003). Generalisability to male adolescents is also limited, and it is plausible that males use digital support seeking in different ways to girls. For example, boys are significantly more likely than girls to engage in online game playing (Colder Carras et al., 2017), which is a specific digital context in which support may be transacted (O'Connor et al., 2015). Future studies with more diverse samples could consider reasons for seeking support online in boys and varied socioeconomic groups.

Second, our study relied on participants' reflections on how frequently they sought support online, and it is possible that less obvious support seeking behaviours (e.g. seeking companionship or reassurance) were underreported by the girls. With several support seeking behaviours now identified, daily diary studies could extend these findings by gathering adolescents' accounts of digital support seeking experiences as they happen. Daily diaries have been used to investigate digital support seeking in young adults (Rife et al., 2016), and offer an additional avenue through which a more nuanced understanding of adolescent digital support seeking can develop. For example, we did not ask the girls in this study to recount the platforms they used to seek support, but daily diary studies may be used to examine whether adolescents engage in different digital support seeking behaviours depending on the online platform used.

Third, our study specifically focused on adolescent girls' digital support seeking from friends. While this narrowed focus was employed to gain an in-depth understanding of this behaviour, there are a number of opportunities to expand understanding of adolescents' digital coping in future studies. For example, while it is expected that girls will increasingly seek support from friends during the early to middle adolescent period, future studies can also investigate the extent to which adolescents seek support electronically from parents and teachers. Further, recent studies have found that adolescents use digital media to enact a number of other coping strategies in addition to support seeking, for example, distraction (Duvenage et al., 2020) and venting (Vermeulen et al., 2018b). Future research can consider why adolescents choose to employ a wider range of digital coping strategies to manage daily stress.

Finally, it is important to note that our interview sampling method only included girls who engaged in some level of digital support seeking. While this was necessary to ensure our interview questions were relevant to the participants, it is possible that adolescents who elect to avoid digital support seeking entirely are more cognizant or identify other limitations of seeking support electronically. These alternative perspectives may extend the understandings derived from the current study and could be included in future study samples. It should also be noted that our questionnaire response rate was relatively low, which may be due to the requirement of opt-in parental consent. As a result, it is possible that adolescents with parents who were particularly interested in their daughter's digital communication use were overrepresented in the sample. Parent interest could reflect concerns about their daughter's use of digital communication, which could influence the frequency of digital support 
seeking findings in this sample. Girls who reported a range of digital support seeking frequencies were selected for the interviews in an attempt to reduce the effects of this potential selection bias.

\section{Conclusion}

This study offers important contributions regarding the frequency of adolescent girls' use of digital support seeking, their reasons for seeking support electronically, and the developmental implications that arose from these electronic communications. The findings show that digital support seeking is a relatively normative experience in the everyday lives of adolescent girls enrolled in affluent schools. Furthermore, most girls participating in the study found this support useful. There were several concerns reported by girls, including issues regarding the trustworthiness of friends in digital interactions and limited reports of negative events. For adults in these girls' lives, however, it is perhaps concerning that some girls perceived emotional avoidance and disinhibition as positive benefits of digital support seeking. These preliminary insights offer avenues for further research that explores both the significance and the developmental implications of digital support in adolescent lives. They also have implications for future study of the nature and type of informal digital contexts that offer the greatest affordances or limitations to the provision of social support, and the development of interventions to support adolescents in using informal digital support sources.

\section{References}

Albert, D., Chein, J., \& Steinberg, L. (2013). The teenage brain: Peer influences on adolescent decision making. Current Directions in Psychological Science, 22(2), 114-120. https://doi.org/10.1177/0963721412471347

Altermatt, E. R. (2007). Coping with academic failure: Gender differences in students' self-reported interactions with family members and friends. The Journal of Early Adolescence, 27(4), 479-508.

https://doi.org/10.1177/0272431607302938

Anderson, M., \& Jiang, J. (2018a, November 28). Teens' social media habits and experiences. Pew Research Center. http://www.pewinternet.org/wp-content/uploads/sites/9/2018/11/PI_2018.11.28_teens-social-media_FINAL4.pdf

Anderson, M., \& Jiang, J. (2018b, May 31). Teens, social media, and technology. Pew Research Center. http://www.pewinternet.org/2018/05/31/teens-social-media-technology-2018/

Australian Bureau of Statistics. (2011). 2011 Census QuickStats.

https://quickstats.censusdata.abs.gov.au/census_services/getproduct/census/2011/quickstat/0

Australian Curriculum, Assessment and Reporting Authority. (2015). About ICSEA.

http://www.acara.edu.au/_resources/About_icsea_2014.pdf

Avenevoli, S., Swendsen, J., He, J.-P., Burstein, M., \& Merikangas, K. R. (2014). Major depression in the national comorbidity survey-adolescent supplement: Prevalence, correlates, and treatment. Journal of the American Academy of Child and Adolescent Psychiatry, 54(1), 37-44. https://doi.org/10.1016/j.jaac.2014.10.010

Bayer, J. B., Ellison, N. B., Schoenebeck, S. Y., \& Falk, E. B. (2016). Sharing the small moments: Ephemeral social interaction on Snapchat. Information, Communication \& Society, 19(7), 956-977.

https://doi.org/10.1080/1369118X.2015.1084349

Best, P., Gil-Rodriguez, E., Manktelow, R., \& Taylor, B. J. (2016). Seeking help from everyone and no-one: Conceptualizing the online help-seeking process among adolescent males. Qualitative Health Research, 26(8), 1067-1077. https://doi.org/10.1177/1049732316648128

Betts, J., Gullone, E., \& Allen, J. S. (2009). An examination of emotion regulation, temperament, and parenting style as potential predictors of adolescent depression risk status: A correlational study. British Journal of Developmental Psychology, 27(2), 473-485. https://doi.org/10.1348/026151008×314900 
Boldero, J., \& Fallon, B. (1995). Adolescent help-seeking: What do they get help for and from whom? Journal of Adolescence, 18(2), 193-209. https://doi.org/10.1006/jado.1995.1013

Bonetti, L., Campbell, M. A., \& Gilmore, L. (2010). The relationship of loneliness and social anxiety with children's and adolescents' online communication. Cyberpsychology, Behavior, and Social Networking, 13(3), 279-285. https://doi.org/10.1089/cyber.2009.0215

Braun, V. \& Clarke, V. (2012). Thematic analysis. In H. Cooper, P. M. Camic, D. L. Long, A. T. Panter, D. Rindskopf, \& K. J. Sher (Eds.), APA handbook of research methods in psychology: Vol. 2. Research designs: Quantitative, qualitative, neuropsychological, and biological (p. 57-71). American Psychological Association.

Bullot, A., Cave, L., Fildes, J., Hall, S., \& Plummer, J. (2017). Mission Australia's 2017 Youth Survey Report. Mission Australia.

Calancie, O., Ewing, L., Narducci, L. D., Horgan, S., \& Khalid-Khan, S. (2017). Exploring how social networking sites impact youth with anxiety: A qualitative study of Facebook stressors among adolescents with an anxiety disorder diagnosis. Cyberpsychology: Journal of Psychosocial Research on Cyberspace, 11(4), Article 2.

https://doi.org/10.5817/CP2017-4-2

Camara, M., Bacigalupe, G., \& Padilla, P. (2017). The role of social support in adolescents: Are you helping me or stressing me out? International Journal of Adolescence and Youth, 22(2), 123-136.

https://doi.org/10.1080/02673843.2013.875480

Campbell, J. L., Quincy, C., Osserman, J., \& Pedersen, O. K. (2013). Coding in-depth semistructured interviews: Problems of unitization and intercoder reliability and agreement. Sociological Methods \& Research, 42(3), 294-320. https://doi.org/10.1177/0049124113500475

Chein, J., Albert, D., O'Brien, L., Uckert, K., \& Steinberg, L. (2011). Peers increase adolescent risk taking by enhancing activity in the brain's reward circuitry. Developmental Science, 14(2), F1-F10.

https://doi.org/10.1111/j.1467-7687.2010.01035.x

Choi, M., \& Toma, C. L. (2014). Social sharing through interpersonal media: Patterns and effects on emotional well-being. Computers in Human Behavior, 36, 530-541. https://doi.org/10.1016/j.chb.2014.04.026

Clarke, A. M., Kuosmanen, T., \& Barry, M. M. (2015). A systematic review of online youth mental health promotion and prevention interventions. Journal of Youth and Adolescence, 44(1), 90-113. https://doi.org/10.1007/s10964014-0165-0

Clarke, V., Braun, V. \& Hayfield, N. (2015). Thematic analysis. In J. A. Smith (Ed.), Qualitative psychology: A practical guide to research methods (3rd ed., pp. 222-248). Sage Publications.

Colarossi, L. G., \& Eccles, J. S. (2003). Differential effects of support providers on adolescents' mental health. Social Work Research, 27(1), 19-30. https://doi.org/10.1093/swr/27.1.19

Colder Carras, M., Van Rooij, A. J., Van de Mheen, D., Musci, R., Xue, Q.-L., \& Mendelson, T. (2017). Video gaming in a hyperconnected world: A cross-sectional study of heavy gaming, problematic gaming symptoms, and online socializing in adolescents. Computers in Human Behavior, 68, 472-479. https://doi.org/10.1016/j.chb.2016.11.060

Compas, B. E. (1998). An agenda for coping research and theory: Basic and applied developmental issues. International Journal of Behavioral Development, 22(2), 231-237. https://doi.org/10.1080/016502598384351

Compas, B. E. (2009). Coping, regulation, and development during childhood and adolescence. New Directions for Child and Adolescent Development, 2009(124), 87-99. https://doi.org/10.1002/cd.245 
Compas, B. E., Connor-Smith, J. K., Saltzman, H., Thomsen, A. H., \& Wadsworth, M. E. (2001). Coping with stress during childhood and adolescence: Problems, progress, and potential in theory and research. Psychological Bulletin, 127(1), 87-127. https://doi.org/10.1037/0033-2909.127.1.87

Cooper, K., Quayle, E., Jonsson, L., \& Svedin, C. G. (2016). Adolescents and self-taken sexual images: A review of the literature. Computers in Human Behavior, 55(Part B), 706-716. https://doi.org/10.1016/j.chb.2015.10.003

Crone, E. A., \& Konijn, E. A. (2018). Media use and brain development during adolescence. Nature Communications, 9, Article 588. https://doi.org/10.1038/s41467-018-03126-x

Crystal, D. S., Kakinuma, M., DeBell, M., Azuma, H., \& Miyashita, T. (2008). Who helps you? Self and other sources of support among youth in Japan and the USA. International Journal of Behavioral Development, 32(6), 496-508. https://doi.org/10.1177/0165025408095554

Davila, J., Hershenberg, R., Feinstein, B. A., Gorman, K., Bhatia, V., \& Starr, L. R. (2012). Frequency and quality of social networking among young adults: Associations with depressive symptoms, rumination, and co-rumination. Psychology of Popular Media Culture, 1(2), 72-86. https://doi.org/10.1037/a0027512

Davis, K. (2012). Friendship 2.0: Adolescents' experiences of belonging and self-disclosure online. Journal of Adolescence, 35(6), 1527-1536. https://doi.org/10.1016/j.adolescence.2012.02.013

DeAndrea, D. C. (2015). Testing the proclaimed affordances of online support groups in a nationally representative sample of adults seeking mental health assistance. Journal of Health Communication, 20(2), 147156. https://doi.org/10.1080/10810730.2014.914606

Donaldson, D., Prinstein, M. J., Danovsky, M., \& Spirito, A. (2000). Patterns of children's coping with life stress: Implications for clinicians. American Journal of Orthopsychiatry, 70(3), 351-359. https://doi.org/10.1037/h0087689

Dudley, D. A., Van Bergen, P., McMaugh, A., \& Mackenzie, E. (2018). The role of social media in developing young people's health literacy. In V. Goodyear \& K. Armour (Eds.), Young people, social media and health (pp. 147-161). Routledge.

Duvenage, M., Correia, H., Uink, B., Barber, B. L., Donovan, C. L., \& Modecki, K. L. (2020). Technology can sting when reality bites: Adolescents' frequent online coping is ineffective with momentary stress. Computers in Human Behavior, 102, 248-259. https://doi.org/10.1016/j.chb.2019.08.024

Eisenberg, N., Fabes, R. A., \& Guthrie, I. K. (1997). Coping with stress. In S. A. Wolchik \& I. N. Sandler (Eds.), Handbook of children's coping: Linking theory and intervention (pp. 41-70). Springer. https://doi.org/10.1007/978-14757-2677-0_2

Ellison, N. B., Steinfield, C., \& Lampe, C. (2007). The benefits of Facebook "friends": Social capital and college students' use of online social network sites. Journal of Computer-Mediated Communication, 12(4), 1143-1168. https://doi.org/10.1111/j.1083-6101.2007.00367.x

Eschenbeck, H., Kohlmann, C., \& Lohaus, A. (2007). Gender differences in coping strategies in children and adolescents. Journal of Individual Differences, 28(1), 18-26. https://doi.org/10.1027/1614-0001.28.1.18

Fallon, B. J., \& Bowles, T. (1999). Adolescent help-seeking for major and minor problems. Australian Journal of Psychology, 51(1), 12-18. https://doi.org/10.1080/00049539908255329

Frison, E., \& Eggermont, S. (2015). The impact of daily stress on adolescents' depressed mood: The role of social support seeking through Facebook. Computers in Human Behavior, 44, 315-325.

https://doi.org/10.1016/j.chb.2014.11.070 
Frydenberg, E. (2008). Adolescent coping: Advances in theory, research and practice (2nd ed.). Routledge. https://doi.org/10.4324/9780203938706

Ging, D., \& O'Higgins Norman, J. (2016). Cyberbullying, conflict management or just messing? Teenage girls' understandings and experiences of gender, friendship, and conflict on Facebook in an Irish second-level school. Feminist Media Studies, 16(5), 805-821. https://doi.org/10.1080/14680777.2015.1137959

Glüer, M., \& Lohaus, A. (2016). Participation in social network sites: Associations with the quality of offline and online friendships in German preadolescents and adolescents. Cyberpsychology: Journal of Psychosocial Research on Cyberspace, 10(2), Article 2. https://doi.org/10.5817/CP2016-2-2

Graham, S. M., Huang, J. Y., Clark, M. S., \& Helgeson, V. S. (2008). The positives of negative emotions: Willingness to express negative emotions promotes relationships. Personality and Social Psychology Bulletin, 34(3), 394-406. https://doi.org/10.1177/0146167207311281

Gunnar, M. R., \& Hostinar, C. E. (2015). The social buffering of the hypothalamic-pituitary-adrenocortical axis in humans: Developmental and experiential determinants. Social Neuroscience, 10(5), 479-488.

https://doi.org/10.1080/17470919.2015.1070747

Hagens, V., Dobrow, M. J., \& Chafe, R. (2009). Interviewee transcript review: Assessing the impact on qualitative research. BMC Medical Research Methodology, 9, Article 47. https://doi.org/10.1186/1471-2288-9-47

Hankin, B. L., Mermelstein, R., \& Roesch, L. (2007). Sex differences in adolescent depression: Stress exposure and reactivity models. Child Development, 78(1), 279-295. https://doi.org/10.1111/j.1467-8624.2007.00997.x

Heerde, J. A., \& Hemphill, S. A. (2018). Examination of associations between informal help-seeking behavior, social support, and adolescent psychosocial outcomes: A meta-analysis. Developmental Review, 47, 44-62. https://doi.org/10.1016/j.dr.2017.10.001

High, A. C., Oeldorf-Hirsch, A., \& Bellur, S. (2014). Misery rarely gets company: The influence of emotional bandwidth on supportive communication on Facebook. Computers in Human Behavior, 34, 79-88. https://doi.org/10.1016/j.chb.2014.01.037

Kauer, S. D., Mangan, C., \& Sanci, L. (2014). Do online mental health services improve help-seeking for young people? A systematic review. Journal of Medical Internet Research, 16(3), Article e66.

https://doi.org/10.2196/jmir.3103

Kiefer, S. M., \& Shim, S. S. (2016). Academic help seeking from peers during adolescence: The role of social goals. Journal of Applied Developmental Psychology, 42, 80-88. https://doi.org/10.1016/j.appdev.2015.12.002

Koutamanis, M., Vossen, H. G. M., \& Valkenburg, P. M. (2015). Adolescents' comments in social media: Why do adolescents receive negative feedback and who is most at risk? Computers in Human Behavior, 53, 486-494. https://doi.org/10.1016/j.chb.2015.07.016

Lawrence, D., Hafekost, J., Johnson, S. E., Saw, S., Buckingham, W. J., Sawyer, M. G., Ainley, J., \& Zubrick, S. R. (2015). Key findings from the second Australian Child and Adolescent Survey of Mental Health and Wellbeing. Australian \& New Zealand Journal of Psychiatry, 50(9), 876-886. https://doi.org/10.1177/0004867415617836

Lewandowski, J., Rosenberg, B. D., Parks, M. J., \& Siegel, J. T. (2011). The effect of informal social support: Face-toface versus computer-mediated communication. Computers in Human Behavior, 27(5), 1806-1814. https://doi.org/10.1016/j.chb.2011.03.008

Lim, V. K. G., Teo, T. S. H., \& Zhao, X. (2013). Psychological costs of support seeking and choice of communication channel. Behaviour \& Information Technology, 32(2), 132-146. https://doi.org/10.1080/0144929x.2010.518248 
Love, B., Crook, B., Thompson, C. M., Zaitchik, S., Knapp, J., LeFebvre, L., Jones, B., Donovan-Kicken, E., Eargle, E., \& Rechis, R. (2012). Exploring psychosocial support online: A content analysis of messages in an adolescent and young adult cancer community. Cyberpsychology, Behavior, and Social Networking, 15(10), 555-559.

https://doi.org/10.1089/cyber.2012.0138

Luthar, S. S., \& Barkin, S. H. (2012). Are affluent youth truly "at risk"? Vulnerability and resilience across three diverse samples. Development and Psychopathology, 24(2), 429-449. https://doi.org/10.1017/S0954579412000089

Luthar S. S., \& Kumar N. L. (2018). Youth in high-achieving schools: Challenges to mental health and directions for evidence-based interventions. In A. W. Leschied, D. H. Saklofske, \& G. L. Flett (Eds.), Handbook of school-based mental health promotion (pp. 441-458). Springer.

Lyman, E. L., \& Luthar, S. S. (2014). Further evidence on the "costs of privilege": Perfectionism in high-achieving youth at socioeconomic extremes. Psychology in the Schools, 51(9), 913-930. https://doi.org/10.1002/pits.21791

Malecki, C. K., \& Demary, M. K. (2002). Measuring perceived social support: Development of the Child and Adolescent Social Support Scale (CASSS). Psychology in the Schools, 39(1), 1-18. https://doi.org/10.1002/pits.10004

Manago, A. M., Taylor, T., \& Greenfield, P. M. (2012). Me and my 400 friends: The anatomy of college students' Facebook networks, their communication patterns, and well-being. Developmental Psychology, 48(2), 369-380. https://doi.org/10.1037/a0026338

McCloskey, W., Iwanicki, S., Lauterbach, D., Giammittorio, D. M., \& Maxwell, K. (2015). Are Facebook "friends" helpful? Development of a Facebook-based measure of social support and examination of relationships among depression, quality of life, and social support. Cyberpsychology, Behavior, and Social Networking, 18(9), 499-505. https://doi.org/10.1089/cyber.2014.0538

Nesi, J., Choukas-Bradley, S., \& Prinstein, M. J. (2018). Transformation of adolescent peer relations in the social media context: Part 1-A theoretical framework and application to dyadic peer relationships. Clinical Child and Family Psychology Review, 21(3), 267-294. https://doi.org/10.1007/s10567-018-0261-x

O'Connor, E. L., Longman, H., White, K. M., \& Obst, P. L. (2015). Sense of community, social identity and social support among players of massively multiplayer online games (MMOGs): A qualitative analysis. Journal of Community \& Applied Social Psychology, 25(6), 459-473. https://doi.org/10.1002/casp.2224

Pabian, S., Erreygers, S., Vandebosch, H., Van Royen, K., Dare, J., Costello, L., Green, L., Hawk, D., \& Cross, D. (2018). "Arguments online, but in school we always act normal": The embeddedness of early adolescent negative peer interactions within the whole of their offline and online peer interactions. Children and Youth Services Review, 86, 1-13. https://doi.org/10.1016/j.childyouth.2018.01.007

Patterson, L. J., Allan, A., \& Cross, D. (2017). Adolescent perceptions of bystanders' responses to cyberbullying. New Media \& Society, 19(3), 366-383. https://doi.org/10.1177/1461444815606369

Peter, J., \& Valkenburg, P. M. (2013). The effects of internet communication on adolescents' psychosocial development: An assessment of risks and opportunities. In E. Scharrer (Ed.), The international encyclopedia of media studies: Vol. 5. Media effects/Media psychology (pp. 678-697). Wiley-Blackwell.

Radovic, A., Gmelin, T., Stein, B. D., \& Miller, E. (2017). Depressed adolescents' positive and negative use of social media. Journal of Adolescence, 55, 5-15. https://doi.org/10.1016/j.adolescence.2016.12.002

Rahdar, A., \& Galván, A. (2014). The cognitive and neurobiological effects of daily stress in adolescents. Neurolmage, 92(Suppl. C), 267-273. https://doi.org/10.1016/j.neuroimage.2014.02.007 
Rains, S. A., Brunner, S. R., Akers, C., Pavlich, C. A., \& Goktas, S. (2017). Computer-mediated communication (CMC) and social support: Testing the effects of using CMC on support outcomes. Journal of Social and Personal Relationships, 34(8), 1186-1205. https://doi.org/10.1177/0265407516670533

Rains, S. A., \& Wright, K. B. (2016). Social support and computer-mediated communication: A state-of-the-art review and agenda for future research. Annals of the International Communication Association, 40(1), 175-211. https://doi.org/10.1080/23808985.2015.11735260

Reich, S. M., Subrahmanyam, K., \& Espinoza, G. (2012). Friending, IMing, and hanging out face-to-face: Overlap in adolescents' online and offline social networks. Developmental Psychology, 48(2), 356-368.

https://doi.org/10.1037/a0026980

Reiss, F. (2013). Socioeconomic inequalities and mental health problems in children and adolescents: A systematic review. Social Science \& Medicine, 90, 24-31. https://doi.org/10.1016/j.socscimed.2013.04.026

Rice, S. M., Goodall, J., Hetrick, S. E., Parker, A. G., Gilbertson, T., Amminger, G. P., Davey, C. G., McGorry, P. D., Gleeson, J., \& Alvarez-Jimenez, M. (2014). Online and social networking interventions for the treatment of depression in young people: A systematic review. Journal of Medical Internet Research, 16(9) Article e206. https://doi.org/10.2196/jmir.3304

Rickwood, D. J., Mazzer, K. R., \& Telford, N. R. (2015). Social influences on seeking help from mental health services, in-person and online, during adolescence and young adulthood. BMC Psychiatry, 15, Article 40. https://doi.org/10.1186/s12888-015-0429-6

Rideout, V., and Robb, M. B. (2018). Social media, social life: Teens reveal their experiences. Common Sense Media. https://www.commonsensemedia.org/sites/default/files/uploads/research/2018_cs_socialmediasociallife_fullrep ort-final-release_2_lowres.pdf

Rife, S. C., Kerns, K. A., \& Updegraff, J. A. (2016). Seeking support in response to social and achievement stressors: A multivenue analysis. Personal Relationships, 23(2), 364-379. https://doi.org/10.1111/pere.12130

Roza, S. J., Hofstra, M. B., van der Ende, J., \& Verhulst, F. C. (2003). Stable prediction of mood and anxiety disorders based on behavioral and emotional problems in childhood: A 14-year follow-up during childhood, adolescence, and young adulthood. American Journal of Psychiatry, 160(12), 2116-2121.

https://doi.org/10.1176/appi.ajp.160.12.2116

Ryan, A. M., \& Shim, S. S. (2012). Changes in help seeking from peers during early adolescence: Associations with changes in achievement and perceptions of teachers. Journal of Educational Psychology, 104(4), 1122-1134. https://doi.org/10.1037/a0027696

Saunders, B., Sim, J., Kingstone, T., Baker, S., Waterfield, J., Bartlam, B., Burroughs, H., \& Jinks, C. (2018). Saturation in qualitative research: Exploring its conceptualization and operationalization. Quality \& Quantity, 52(4), 1893-1907. https://doi.org/10.1007/s11135-017-0574-8

Schouten, A. P., Valkenburg, P. M., \& Peter, J. (2007). Precursors and underlying processes of adolescents' online self-disclosure: Developing and testing an "Internet-attribute-perception" model. Media Psychology, 10(2), 292315. https://doi.org/10.1080/15213260701375686

Schwartz-Mette, R. A., \& Rose, A. J. (2012). Co-rumination mediates contagion of internalizing symptoms within youths' friendships. Developmental Psychology, 48(5), 1355-1365. https://doi.org/10.1037/a0027484

Schwieger, T., Campo, S., Steuber, K. R., Weinstein, S. L., \& Ashida, S. (2016). An exploration of information exchange by adolescents and parents participating in adolescent idiopathic scoliosis online support groups. Scoliosis and Spinal Disorders, 11, Article 22. https://doi.org/10.1186/s13013-016-0084-9 
Seiffge-Krenke, I. (1995). Stress, coping, and relationships in adolescence. Erlbaum.

Selfhout, M. H. W., Branje, S. J. T., Delsing, M., ter Bogt, T. F. M., \& Meeus, W. H. J. (2009). Different types of Internet use, depression, and social anxiety: The role of perceived friendship quality. Journal of Adolescence, 32(4), 819-833. https://doi.org/10.1016/j.adolescence.2008.10.011

Skinner, E. A., Edge, K., Altman, J., \& Sherwood, H. (2003). Searching for the structure of coping: A review and critique of category systems for classifying ways of coping. Psychological Bulletin, 129(2), 216-269.

https://doi.org/10.1037/0033-2909.129.2.216

Skinner, E. A., \& Zimmer-Gembeck, M. J. (2016). The development of coping: Stress, neurophysiology, social relationships, and resilience during childhood and adolescence. Springer International Publishing.

Smith, J. A. (2015). Qualitative psychology: A practical guide to research methods (3rd ed.). Sage.

Spears, B. A., Taddeo, C. M., Daly, A. L., Stretton, A., \& Karklins, L. T. (2015). Cyberbullying, help-seeking and mental health in young Australians: Implications for public health. International Journal of Public Health, 60(2), 219-226. https://doi.org/10.1007/s00038-014-0642-y

Spencer, R., Walsh, J., Liang, B., Desilva Mousseau, A. M., \& Lund, T. J. (2018). Having it all? A qualitative examination of affluent adolescent girls' perceptions of stress and their quests for success. Journal of Adolescent Research, 33(1), 3-33. https://doi.org/10.1177/0743558416670990

Spies Shapiro, L. A., \& Margolin, G. (2014). Growing up wired: Social networking sites and adolescent psychosocial development. Clinical Child and Family Psychology Review, 17(1), 1-18.

https://doi.org/10.1007/s10567-013-0135-1

Steinberg, L. (2005). Cognitive and affective development in adolescence. Trends in Cognitive Sciences, 9(2), 69-74. https://doi.org/10.1016/j.tics.2004.12.005

Stone, L. B., Hankin, B. L., Gibb, B. E., \& Abela, J. R. Z. (2011). Co-rumination predicts the onset of depressive disorders during adolescence. Journal of Abnormal Psychology, 120(3), 752-757. https://doi.org/10.1037/a0023384

Suler, J. (2004). The online disinhibition effect. CyberPsychology \& Behavior, 7(3), 321-326.

https://doi.org/10.1089/1094931041291295

Tanis, M. (2007). Online social support groups. In A. Joinson, K. McKenna, T. Postmes, \& U. D. Reips (Eds.), The Oxford handbook of Internet psychology (pp. 139-154). Oxford University Press.

Thomas, D. R. (2006). A general inductive approach for analyzing qualitative evaluation data. American Journal of Evaluation, 27(2), 237-246. https://doi.org/10.1177/1098214005283748

Trepte, S., Dienlin, T., \& Reinecke, L. (2015). Influence of social support received in online and offline contexts on satisfaction with social support and satisfaction with life: A longitudinal study. Media Psychology, 18(1), 74-105. https://doi.org/10.1080/15213269.2013.838904

Underwood, M. K., Ehrenreich, S. E., More, D., Solis, J. S., \& Brinkley, D. Y. (2015). The Blackberry project: The hidden world of adolescents' text messaging and relations with internalizing symptoms. Journal of Research on Adolescence, 25(1), 101-117. https://doi.org/10.1111/jora.12101

Utz, S., \& Breuer, J. (2017). The relationship between use of social network sites, online social support, and wellbeing: Results from a six-wave longitudinal study. Journal of Media Psychology, 29(3), 115-125.

https://doi.org/10.1027/1864-1105/a000222 
Valkenburg, P. M., \& Peter, J. (2009). The effects of instant messaging on the quality of adolescents' existing friendships: A longitudinal study. Journal of Communication, 59(1), 79-97. https://doi.org/10.1111/j.1460-

2466.2008.01405.x

Valkenburg, P. M., Peter, J., \& Schouten, A. P. (2006). Friend networking sites and their relationship to adolescents' well-being and social self-esteem. CyberPsychology \& Behavior, 9(5), 584-590.

https://doi.org/10.1089/cpb.2006.9.584

Vermeulen, A., Vandebosch, H., \& Heirman, W. (2018a). Shall I call, text, post it online or just tell it face-to-face? How and why Flemish adolescents choose to share their emotions on- or offline. Journal of Children and Media, 12(1), 81-97. https://doi.org/10.1080/17482798.2017.1386580

Vermeulen, A., Vandebosch, H., \& Heirman, W. (2018b). \#Smiling, \#venting, or both? Adolescents' social sharing of emotions on social media. Computers in Human Behavior, 84, 211-219.

https://doi.org/10.1016/j.chb.2018.02.022

Walther, J. B., Van Der Heide, B., Ramirez, A., Jr., Burgoon, J. K., \& Peña, J. (2015). Interpersonal and hyperpersonal dimensions of computer-mediated communication. In S. S. Sundar (Ed.), The handbook of the psychology of communication technology (pp. 1-22). John Wiley \& Sons. https://doi.org/10.1002/9781118426456.ch1

Waters, S. K., Lester, L., \& Cross, D. (2014). Transition to secondary school: Expectation versus experience. Australian Journal of Education, 58(2), 153-166. https://doi.org/10.1177/0004944114523371

Weinstein, E. C., \& Selman, R. L. (2016). Digital stress: Adolescents' personal accounts. New Media \& Society, 18(3), 391-409. https://doi.org/10.1177/1461444814543989

West, P., \& Sweeting, H. (2003). Fifteen, female and stressed: Changing patterns of psychological distress over time. Journal of Child Psychology and Psychiatry, 44(3), 399-411. https://doi.org/10.1111/1469-7610.00130

White, A. E., Weinstein, E., \& Selman, R. L. (2018). Adolescent friendship challenges in a digital context: Are new technologies game changers, amplifiers, or just a new medium? Convergence: The International Journal of Research into New Media Technologies, 24(3), 269-288. https://doi.org/10.1177/1354856516678349

Wilson, C. J., Deane, F. P., Ciarrochi, J., \& Rickwood, D. (2005). Measuring help-seeking intentions: Properties of the General Help-Seeking Questionnaire. Canadian Journal of Counselling and Psychotherapy, 39(1), 15-28.

https://cjc-rcc.ucalgary.ca/article/view/58748

Zahn-Waxler, C., Shirtcliff, E. A., \& Marceau, K. (2008). Disorders of childhood and adolescence: Gender and psychopathology. Annual Review of Clinical Psychology, 4, 275-303.

https://doi.org/10.1146/annurev.clinpsy.3.022806.091358

Ziegele, M., \& Reinecke, L. (2017). No place for negative emotions? The effects of message valence, communication channel, and social distance on users' willingness to respond to SNS status. Computers in Human Behavior, 75, 704-713. https://doi.org/10.1016/j.chb.2017.06.016

Zimmer-Gembeck, M. J., \& Skinner, E. A. (2008). Adolescents coping with stress: Development and diversity. Prevention Researcher, 15(4), 3-7.

Zimmer-Gembeck, M. J., \& Skinner, E. A. (2011). Review: The development of coping across childhood and adolescence: An integrative review and critique of research. International Journal of Behavioral Development, 35(1), 1-17. https://doi.org/10.1177/0165025410384923

Zimmer-Gembeck, M. J., \& Skinner, E. A. (2016). The development of coping: Implications for psychopathology and resilience. In D. Cicchetti (Ed.), Developmental psychopathology Nol. 4., pp. 485-544). John Wiley \& Sons. https://doi.org/10.1002/9781119125556.devpsy410 


\section{Correspondence to:}

Erin Mackenzie

Centre for Educational Research, Western Sydney University

Locked Bag 1797 Penrith

NSW 2751

Australia

Email: e.mackenzie(at)westernsydney.edu.au

Editorial record: First submission received on June 14, 2019. Revisions received on March 12, 2020, May 12, 2020 and May 22, 2020. Accepted for publication on May 27, 2020.

Editor in charge: Lenka Dedkova

\section{About Authors}

Erin Mackenzie, PhD, is a Lecturer in the School of Education and a researcher in the Centre for Educational Research at Western Sydney University. Her research interests include adolescent online interactions, coping, and the role of psychological and social factors in adolescent girls' participation in STEM education.

Anne McMaugh, PhD, is a Senior Lecturer of Educational Psychology at Macquarie University. Her research interests include social and emotional development of children and youth including peer relationships, aggression, and bullying and social outcomes for vulnerable child populations.

Penny Van Bergen, PhD, is an Associate Professor of Educational Psychology at Macquarie University, Sydney, Australia. As Director of the Centre for Children's Learning in a Social World, she is interested in how social interactions and relationships shape child and adolescent development and wellbeing. 